\title{
Determination of the Rational Number of Cutters on the Outer Cutting Drums of Geokhod
}

\author{
Alexey KHORESHOK ${ }^{1, *}$, Kirill ANANIEV ${ }^{2}$, Alexander ERMAKOV ${ }^{3}$, Dilshad KUZIEV ${ }^{4}$ \\ and Alexander BABARYKIN ${ }^{5}$
}

Authors' affiliations and addresses: ${ }^{1}$ T.F. Gorbachev Kuzbass State Technical University, Mining machines Department, 650000 Kemerovo, 28 Vesennya st., Russian Federation

e-mail: haa.omit@kuzstu.ru

${ }^{2}$ T.F. Gorbachev Kuzbass State Technical University, Mining machines Department, 650000 Kemerovo, 28 Vesennya st., Russian Federation

e-mail: aka.kgmik@kuzstu.ru

${ }^{3}$ T.F. Gorbachev Kuzbass State Technical University, Mining machines Department, 650000 Kemerovo, 28 Vesennya st., Russian Federation

e-mail: ermakovan@kuzstu.ru

${ }^{4}$ National University of Science and Technology «MISiS», 119049 Moscow, 6 Leninskiy avenue, Russian Federation e-mail: akablack@list.ru

${ }^{5}$ T.F. Gorbachev Kuzbass State Technical University, Mining machines Department, 650000 Kemerovo, 28 Vesennya st., Russian Federation

e-mail: aleksandr_babarikin@mail.ru

\section{*Correspondence:}

Alexey Khoreshok, 650000 Kemerovo, 28

Vesennya st., Russian Federation,

tel: +7(3842)396379

e-mail: $\underline{\text { haa.omit@kuzstu.ru }}$

Funding information:

The research was sponsored by Grant of the President of the Russian Federation for state support of young Russian scientists MK-664.2018.8.

How to cite this article:

Khoreshok, A., Ananiev, K., Ermakov, A.,

Kuziev, D., and Babarykin, A. (2020).

Determination of the Rational Number of

Cutters on the Outer Cutting Drums of

Geokhod. Acta Montanistica Slovaca, Volume 25 (1), $70-80$

DOI:

https://doi.org/10.46544/AMS.v25i1.7

\begin{abstract}
The issue of substantiation and choice of a rational number of cutters on the outer cutting drums of the geokhod for the formation of grooves in medium strength rocks is considered in this article. It is established that the coefficient of variation of the torque must be taken into account while determining the number of cutters. It is established that the required feed velocities are realized with a crown-type outer cutting drum at one or two cutters in the cutting lines, and the coefficient of torque variation does not exceed $20 \%$ at any allowable number of cutters and equal lag angle. On the disktype outer cutting drum required feed velocities are realized with the number of cutters in the cutting lines from 1 to 4 . The minimum number of cutters providing a coefficient of variation of the torque on the disk-type outer cutting drum above the set depends on the angle of coverage and reduces with the increase of the angle of coverage. The example of schematic designs of OCD AR and OCD EP development is shown for a prototype model of geokhod $(3.2 \mathrm{~m}$ diameter) using the obtained expressions to determine the basic geometric, kinematic, force, and structural parameters. The possibility of decision making of the type of OCD for geokhod and its creation is confirmed. The documentation design documents for production crown-type OCD for a prototype of geokhod were developed based on the conducted research.
\end{abstract}

\section{Keywords}

tunneling, geokhod, cutting drum, picks, cutting lines.

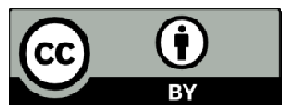

(C) 2020 by the authors. Submitted for possible open access publication under the terms and conditions of the Creative Commons Attribution (CC BY) license (http://creativecommons.org/licenses/by/4.0/). 


\section{Introduction}

The study of the underground space formation and the development of the subsoil are very important for the life of mankind and affect the development associated with the creation of new technologies for the construction of a network of underground transportation traffic, the construction of highways and railways at a considerable depth.

The construction of the underground mines, city highways, and subway tunnels is a laborious and expensive process. The most important tasks are increasing the rate of penetration, productivity, safety, and reduce the cost of work.

The traditional representation of excavation, as the process of cavity formation in rocks, has always defined and still determines the directions for improving the technologies for the construction of underground structures and the creation of tunneling equipment for the development of underground space. However, the well-known technologies of mining, developing along the path of increasing the power and metal consumption of equipment, have practically exhausted their possibilities in increasing productivity, ensuring the safety of workers, and expanding the scope.

Further development of work in the field of geotechnology and geotechnics can be performed in two directions:

- modernization of the existing mining equipment and its improvement by creating systems of a new technical level;

- search and creation of a fundamentally new, alternative toolkit (technologies and geotechnics) for the development of the subsoil and the formation of underground space.

In underground conditions, external propulsions are used to move the tunneling machines: tracked, wheeled, or wheel-rail. Propulsors which have proved themselves well working on the ground surface (at the contact of solid and air), are not adapted for movement in the geological environment.

From this circumstance, the main problems of modern technologies of mine workings follow:

- the impossibility of movement of the boring apparatus in any direction of the underground space;

- the impossibility of creating large pressure forces on the executive body for the destruction of hard rock.

As a result, to create sufficient pressure, the designers are forced to increase the weight of mining machines, which already reaches 80-100 tons. In addition, safety issues in the face zone continue to be acute.

In the course of work of the tunneling machine or shield, in order to create the force of thrust and pressure force on the cutting drum, the external media itself is not involved in any way, but only the solid surface of the excavation at the contact of the geo and air environments, or with the shield method of penetration - strong permanent support.

For a number of years in Russia, the team of authors has been working on the creation of a new type of mining technology. The idea of the work is based on the proposal to consider the excavation of mine workings initially as a process of movement of a solid body in the environment of the host rocks. At the same time, the rock is used as a supporting element, participating in the creation of the driving force of the tunneling machine and the pressure force on the cutting drums, as well as for performing the basic technological operations, including fixing the production of permanent support.

The principle of functional unification of the main movement (submission to the face) and the process of cutting rocks gave the name "geowinchester" technology for mining.

"Geowinchester technology" is a set of processes for the mechanized conduct of mine workings with the formation and use of a system of the boring screw and longitudinal grooves, where the processes for the development of the face, the cleaning of the rock, the fixation of the developed space, and the movement of the entire tunneling system to the face, are carried out in a combined mode. The involvement of the rock is achieved by introducing an additional technological operation - the formation of a system of outer grooves (Fig. 1).

On the basis of the functional-structural theory of the creation of mining systems, a prototype model of a tunneling unit was developed, the distinctive feature of which is the rotational-progressive movement to the face according to the principle of screwing. At present, this type of mining machines has been called the geokhod (Fig. 2).

As noted earlier, a characteristic feature of the technology of excavation using geokhods is the formation of grooves beyond the contours of the works. Screw grooves are involved in the conversion of transmission torque to the pressure force at the bottom. To stabilize the tail section, longitudinal grooves are formed. In the rocks of medium and high strength, the formation of grooves requires the use of active limiting executive bodies. 


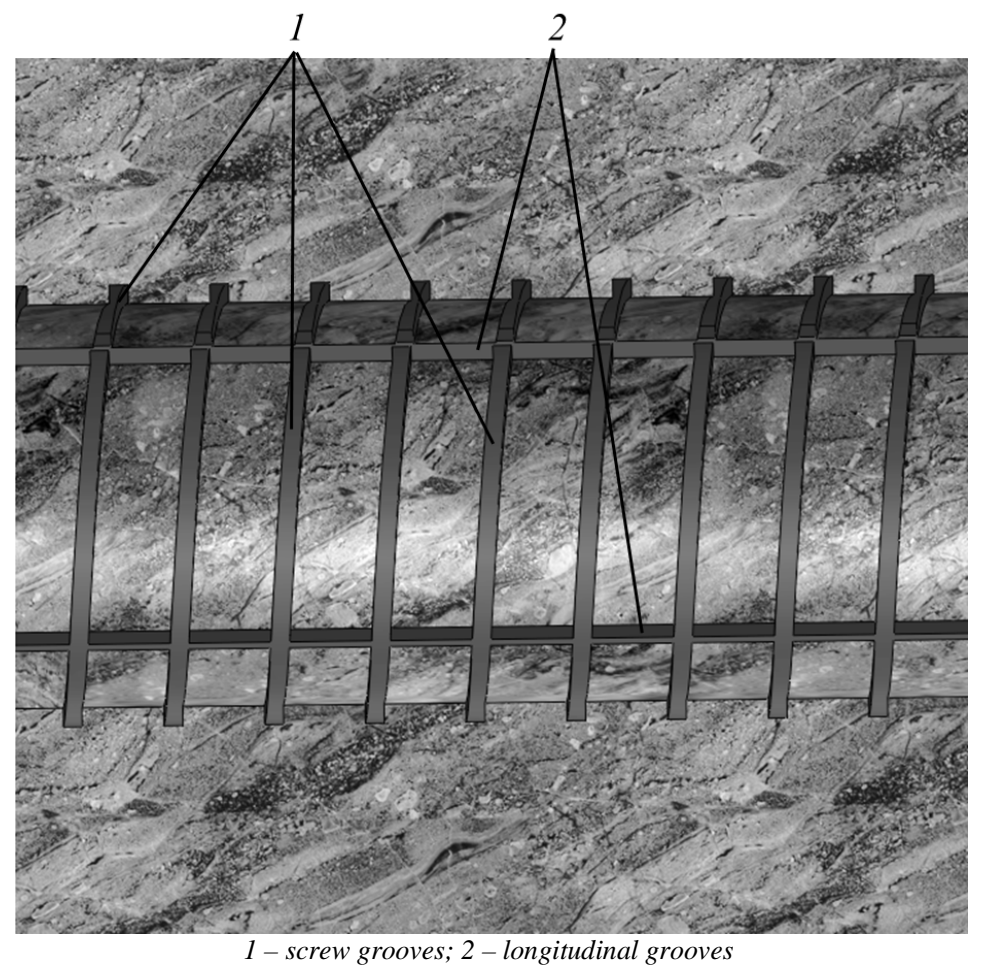

Fig. 1. Longitudinal cross-section of the mine with formed behind-contour grooves

The geokhod is a shield tunnel boring machine by which underground moves are carried out due to interaction with the geo-environment (Blashchuk et al., 2014; Chernukhin et al., 2015; Sadovets et al., 2015). In recent years, a team of authors is working on creating geokhod for work in rocks of medium strength (Figure 2) (Aksenov et al., 2015; Aksenov et al., 2019).

The main cutting drums of the geokhod for the formation of contours of heading has a number of prototypes in traditional mining machines (Jang et al., 2016). At the same time, the system for the grooves formation out of the contours of the heading was not previously used in such complexes. As options, two types of outer cutting drums (OCD) were proposed: disk-type and crown-type (Fig. 3).
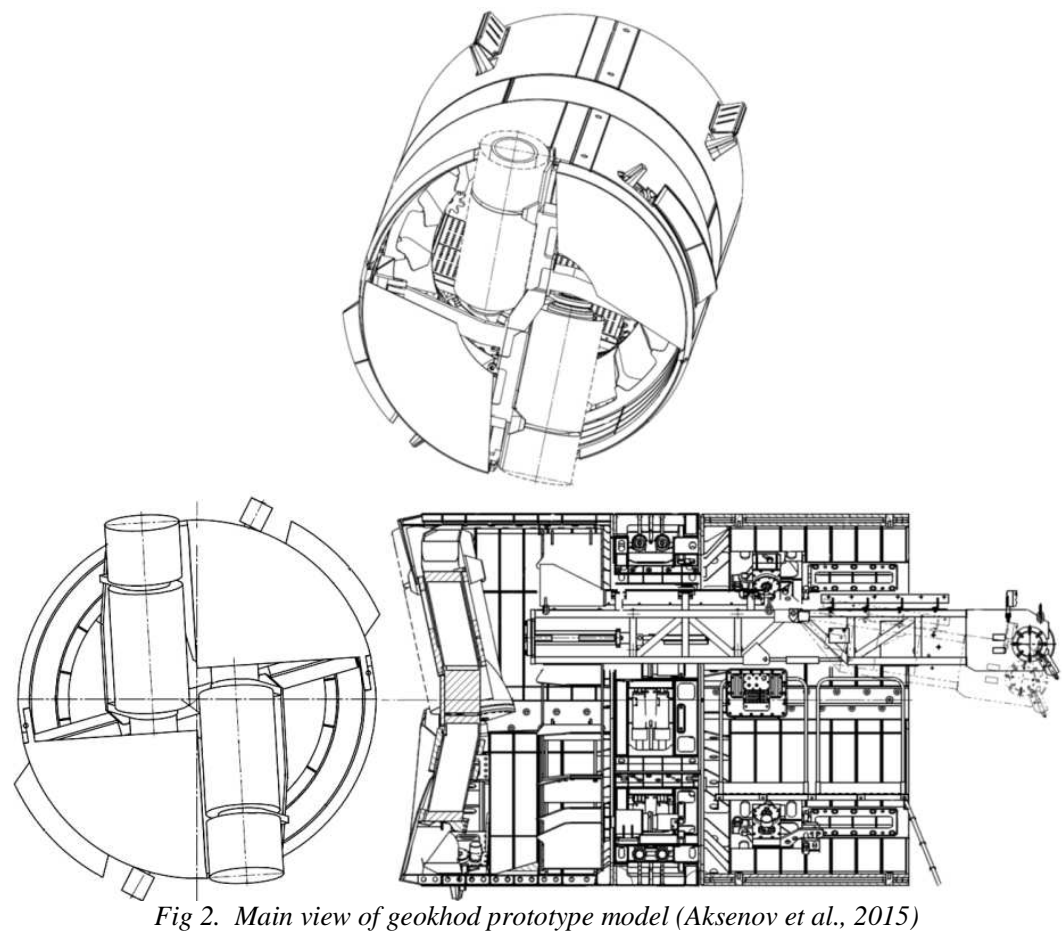


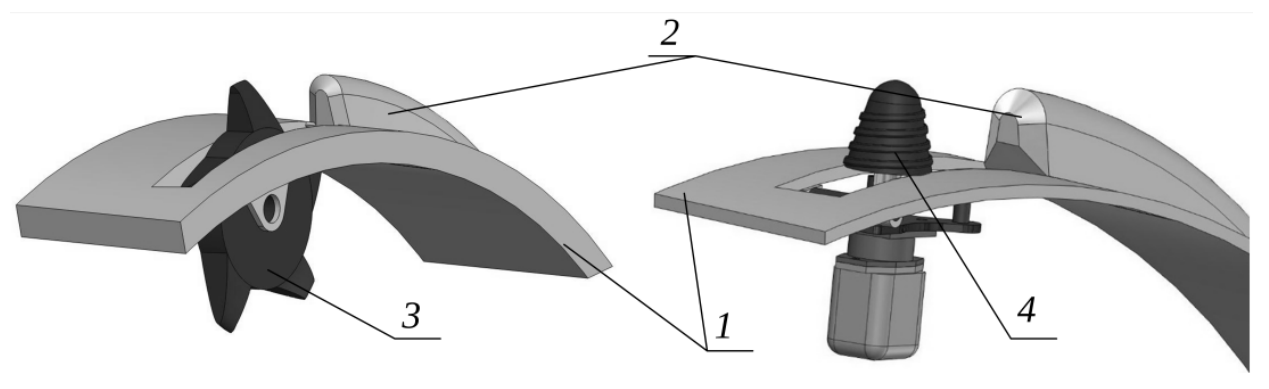

1 - geokhod's shield; 2 - screw blade; disk-type groove cutter; 4 - crown-type cutter

Fig 3. Schemes of the geokhod's OCDs

A comparison and evaluation of the proposed solutions require the algorithm for the arrangement of cutters on OCD. The task of the arrangement of the cutters is reduced to determining their rational number, taking into account the coefficients of variation $(\mathrm{CV})$ loads, the characteristics of the rock, and the requirements for the specific energy of destruction (Balci, 2013; Hekimoglu and Fowell, 1991).

When choosing a scheme of the arrangement of the cutters, two conditions must be fulfilled: ensuring equal chip thickness and a minimum number of cutters. The first condition will ensure the possibility of comparing the results obtained with respect to the specific energy of destruction, and the second is a necessary condition for saving the most expensive part of the cutting drum (the hard alloy of the cutters).

\section{Methods}

The number of cutters on OCD regardless of type, can be defined as (Methodology. Shearers...,1984):

$$
n_{c}=\sum_{i=1}^{n_{l . n}} n_{c . l . i}
$$

In the type: nl.n stands for the number of cutting lines.

The number of cutters in the i-cutting line (Methodology. Shearers...,1984):

$$
n_{c . l . i}=\frac{V_{F O C D}}{h_{\max } n_{O C D}}
$$

In the type: $\mathrm{V}_{\mathrm{FOCD}}$ stands for the feed velocity of OCD; $\mathrm{h}_{\max }$ is the maximum cutting depth; $\mathrm{n}_{\mathrm{OCD}}$ is OCD rotation frequency.

According to the recommendations (Baron et al., 1968) maximum cutting depth is set equal to $16 \mathrm{~mm}$ for the medium strength rocks. Larger values of the maximum cutting depth will lead to increased force on the cutting edges. At a small cutting depth values, the formation of the fissure collapse does not occur, which leads to a significant increase in the specific energy of destruction and increased tool wear (Wingquist and Hanson, 1987).

The feed velocity of OCD in the groove, on the one hand, is determined by the required feed rate of geokhod, and on the other depends on the number of cutters in the cutting line. The required feed velocity of OCD can be represented as:

$$
V_{F O C D}=\sqrt{\left(\frac{V_{F g}\left(D_{g}+2 h_{g}\right.}{D_{g} \operatorname{tg}(\beta)}\right)^{2}+V_{F g}^{2}}
$$

The explanations of the parameters and their values set for the study are presented in Table 1.

Table 1. The parameters of geokhod and OCD

\begin{tabular}{|c|c|c|}
\hline Pable 1. The parameters of geokhod and $O C D$ & Designation & Value \\
\hline Feed velocity of geokhod & $\mathrm{VFg}$ & $7[\mathrm{~m} / \mathrm{hr}]$ \\
\hline The outer diameter of geokhod & $\mathrm{Dg}$ & $2,1 \div 5,6[\mathrm{~m}]$ \\
\hline The height of the outer groove formed by OCD & $\mathrm{hg}$ & $0,1 \div 0,4[\mathrm{~m}]$ \\
\hline The helix angle of the screw blade & $\beta$ & $4 \div 20[\mathrm{deg}]$ \\
\hline
\end{tabular}


The OCD rotation frequency can be represented as a function of the cutting velocity

$$
n_{O C D}=\frac{V_{c}}{\pi D_{O C D}}
$$

In the type: $\mathrm{V}_{\mathrm{c}}$ stands for the cutting velocity; $\mathrm{D}_{\mathrm{OCD}}$ is the diameter of OCD by cutters.

The maximum acceptable cutting velocity can be set in accordance with the recommendations of the research (Chang et al., 2006; Dogruoz et al., 2015). At the high cutting velocity (more than $2.0 \mathrm{~m} / \mathrm{s}$ ), the intensive wear of the cutters occurs due to its overheating. In addition, in a number of experimental studies, the preferability of cutting of rocks with low cutting velocity was proved (Hurt and MacAndrew, 1985). The limitation of the cutting velocity is another condition that will lead to an increase in the number of cutters in the cutting lines in some schemes of the OCD.

Substituting into equation (2) equation (4) and expressing the feed velocity of OCD, we obtain an expression for determining the feed velocity of OCD with a given number of cutters in the cutting line (possible feed velocity of OCD).

$$
V_{F O C D}=\frac{n_{c . l . i} V_{c} h_{\max }}{\pi D_{g}}
$$

The number of cutting lines is determined by the distance between the adjacent cutting lines (so-called cutting step). Another feature of the geokhod's OCDs is the work in the groove, that is, in conditions typical for the peripheral parts of the cutting drums of coal mining and tunneling machines (Xuefeng et al., 2018). For the accepted cutting depth and tool width (b), the cutting step, $t_{\text {opt }}$, can be determined from the expression

$$
t_{\text {opt }}=b+1.3 h_{\max } \text {. }
$$

The number of cutting lines $\left(n_{l . n}\right)$ for crown-type OCD is determined by the height of the groove, and for the disk-type OCD by the groove width:

$$
n_{l . n}=\frac{h_{O C D}}{t_{\text {opt }}} \text {. }
$$

In the formula: $\mathrm{h}_{\mathrm{OCD}}$ stands for the height of OCD.

The number of cutting lines for disk-type OCD and small groove width is equal to one that is not advisable since the cutter will be in the locked cut mode. Therefore, it is rational to take at least two cutting lines.

Relatively low values of feed velocity of OCD allow the use of schemes with a small number of cutters. At the same time, the values of torque CV can be much higher than CV of the traditional cutting drums. It is caused by a smaller number of cutters in contact with the rock and a significant fluctuation of this number (Li et al., 2013; Ermakov, 2016).

In accordance with (Ermakov, 2016) the torque $\mathrm{CV}$ is defined as

$$
\begin{aligned}
& k_{B}=\frac{\sigma_{M}}{x_{M}}, \\
& \sigma_{M}=\sqrt{\frac{1}{n-1} \sum_{j=1}^{n}\left(x_{j}-x_{M}\right)^{2}} \\
& x_{M}=\frac{1}{n} \sum_{j=1}^{n} x_{j},
\end{aligned},
$$

In the formula: $\sigma_{M}$ stands for the mean square deviation of torque on OCD; $x_{M}$ is the expected value of torque on OCD; $n$ is the number of observations in the sample; $x_{j}$ is the current torque value; $j$ is the number of the OCD considered position

The current torque value can be represented as

$$
x_{j}=\frac{D_{O C D} \sum_{i=1}^{n_{c}} P z_{i j}}{2} \text {. }
$$

Where $P z_{i j}$ is the cutting force on $i$-cutter in a $j$-position of OCD.

In accordance with (Baron, et al., 1968), the cutting force is determined by an expression that can be represented in a general form: 


$$
P z_{i j}=f\left(h_{\max }, \varphi_{c o v}, t_{o p t}, f, F_{r}\right)
$$

In the type: $F_{r}$ are the parameters that characterize the geometry of the cutter (a type of cutter, a shape of the head of the holder, a width of the cutting edge, a shape of the front face, cutting angle and etc.), $f$ is Protodyakonov rock strength.

\section{Results and Discussion}

Taking the number of cutters in the cutting line is discrete from one to four; the maximum possible feed velocities were determined from the expression (5). As the diameter of the OCD increases or the number of cutters in the cutting line decreases, the possible feed velocity of the OCD decreases (the cutting velocity is assumed constant). Figure 4 shows the joint graphs of the possible and necessary velocities of the submission of OCD.

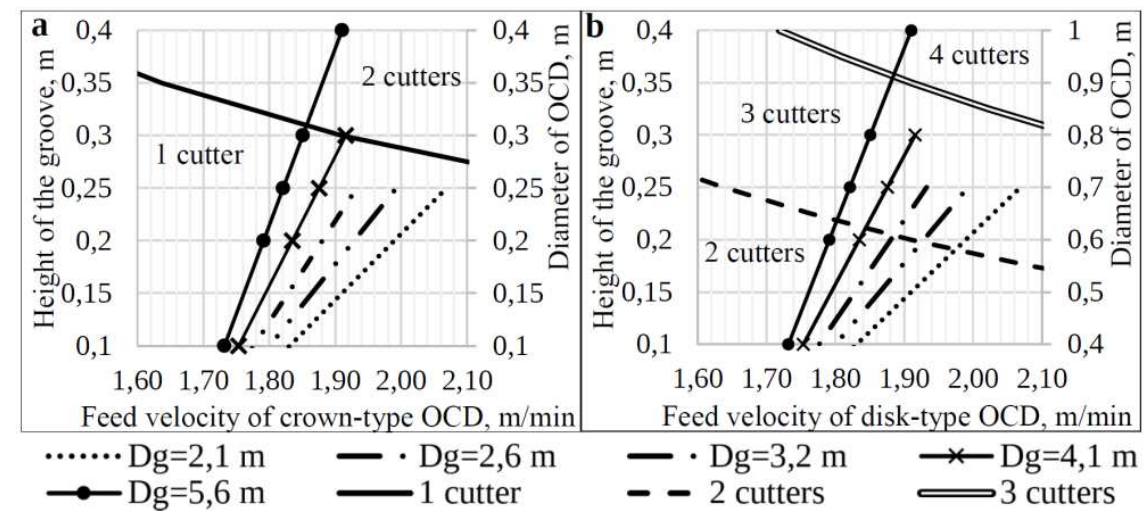

Fig 4. The diameter of the OCD and the height of the groove depending on the required and possible feed velocity

The curve "1 cutter" (Figure 4, a) shows the maximum feed velocity at one cutter in the cutting line and limits the area below which a single-cutter can work in the cutting line at the accepted cutting velocity and cutting depth. For disk-type OCD (Figure 4, b), the areas on the graph between the curves denoted by the number of cutters correspond to the maximum feed velocity with the number of cutters in the cutting line corresponding to the number of the curve bounding the area from above.

Based on the analysis of the graphs, it is established that for the crown-type OCD of any diameters and groove heights, the required feed velocity is achieved with one cutter in the cutting lines. Exceptions are the diameter of the geokhod $5.6 \mathrm{~m}$, and the height of the groove is more than $0.31 \mathrm{~m}$. In this case, two cutters in the cutting lines are required to realize the required feed velocity. The required feed velocity for the disk-type OCD is realized with the number of cutters from one to four for any diameter of the disk. In this case, four cutters in the cutting lines are required only for the groove height of more than $0.35 \mathrm{~m}$ and a diameter of the geokhod 5.6 $\mathrm{m}$. In all other cases, one to three cutters in the cutting lines are sufficient.

For some of the schemes of cutters arrangement, the minimum required CV for the OCD is not provided. It is necessary to specify the minimum number of cutters for this condition. Since CV does not depend on absolute values of forces and torque, it is possible to evaluate it at the early stages of design when choosing the number of cutters. The CV was evaluated according to expressions (8) - (11) (OCD forms a groove of rectangular crosssection, the cutters are placed with the same angle lag, the number of cutters from 5 to 60 ). The cutting forces were determined by the simulation in the Matlab / Simulink environment. It has been established that the angle of coverage and the number of cutters on the OCD have the greatest influence on CV.

The CV obtained for crown-type OCD is acceptable and does not exceed $10 \%$ for any number of cutters, but it can be reduced by increasing the number of cutters. The increase in the total number of cutters is achieved by increasing the number of cutters in the cutting lines, and, therefore, occurs with a step equal to the number of cutting lines. It is not always rational to produce such an increase.

The coverage angle of the disk OCD determines the entry and exit points of the cutters from the contact with the rocks, which in turn affects the shape of the chips on the OCD and the nature of the torque variation on the OCD. Dependences of CV on disk-type OCD on the number of cutters at angles of coverage of 60 and 90 degrees are presented in Figure 5. 


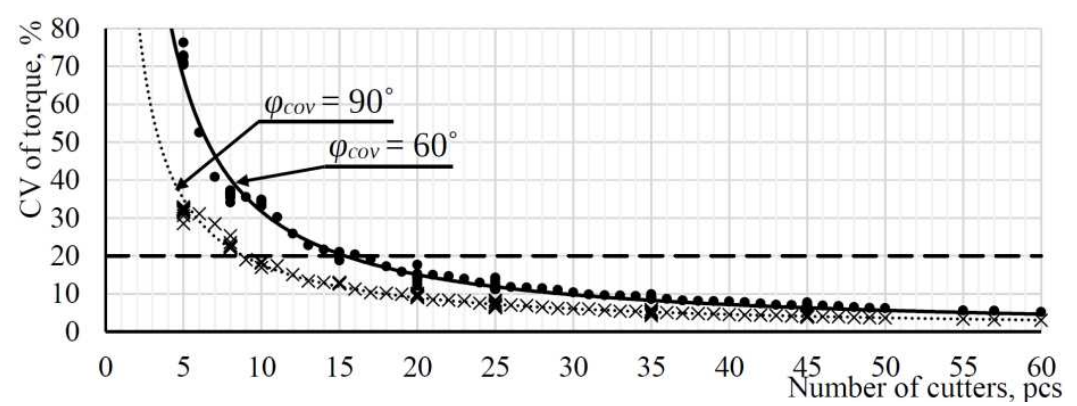

Fig 5. Dependence of $C V$ on the disk-type OCD on the number of cutters at different angles of coverage

The points on the graph are approximated by power functions $\left(\mathrm{R}^{2}=0.98\right)$. CV values (unlike crown-type OCD) can significantly exceed the critical value (20\% is indicated by a horizontal line). At a 90-degree angle of coverage, the CV exceeds $20 \%$ with 9 cutters, and at 60 degrees with 15 cutters, which is unacceptable. According to the graphs in Fig. 5, it is possible to determine the minimum number of cutters, at which CV does not exceed 20\% for angles of coverage of 60 and 90 degrees. Similarly, for angles of coverage in the range of 60 to 90 degrees in 1-degree increments, the minimum cutter numbers were obtained to provide a CV of at least 10 , 20, 30 and 40\%. In Figure 6, the values obtained are presented graphically.

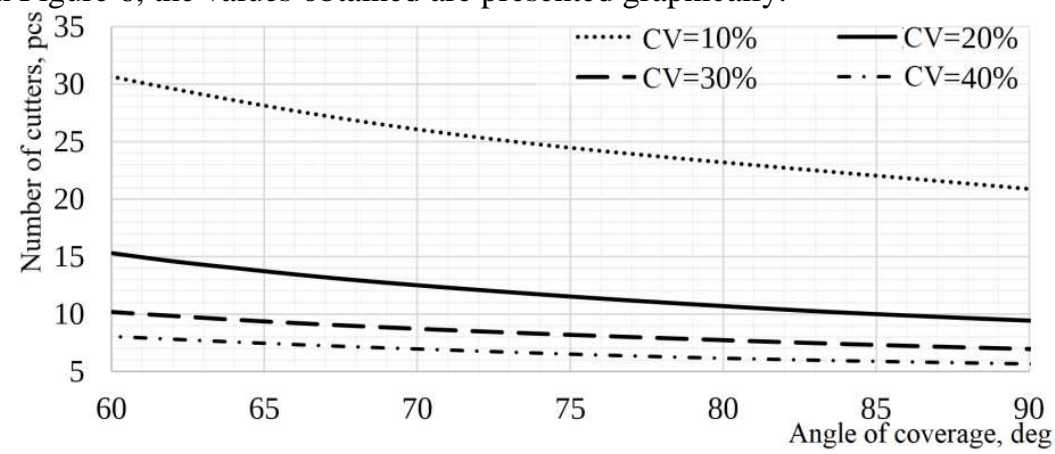

Fig 6. Dependence of the minimum number of cutters on the disk-type OCD on the angle of coverage

The curves limit from above the region in which the CV appears to be over the preset value. At a known coverage angle in accordance with Figure 6, the minimum number of cutters for a disk-type OCD can be determined by the condition of providing a given CV. To provide a CV comparable to a crown-type OCD, the total number of cutters on a disk-type OCD should exceed 20 pieces at a 90-degree coverage angle and 30 pieces at a coverage angle of 60 degrees.

As an example, the development of schemes and the determination of the main parameters of the OCD for a prototype of a geokhod $3.2 \mathrm{~m}$ in diameter are considered. The initial data for the calculation are presented in Table 2. The layout and the number of OCDs on the geokhod correspond to the scheme in Figure 2. For the initial ones presented in Table 2 of data, it is necessary to develop schemes both the disk and crown types of OCD of external propulsor (EP) and OCD of the anti-rotation elements (AR). It will make it possible to decide on the further constructive study of the options.

\begin{tabular}{|c|c|c|c|}
\hline Parameter & \multicolumn{2}{|c|}{ Value } & Units \\
\hline The outer diameter of geokhod & \multicolumn{2}{|c|}{3,2} & [m] \\
\hline Protodyakonov rock strength & \multicolumn{2}{|c|}{5} & [pcs] \\
\hline The helix angle of the screw blade & \multicolumn{2}{|c|}{4,55} & {$\left[{ }^{\circ}\right]$} \\
\hline Rotations per minute of geokhod & \multicolumn{2}{|c|}{0,1} & {$[\mathrm{rpm}]$} \\
\hline \multirow[t]{2}{*}{ The lead of helix of the screw blade } & \multicolumn{2}{|c|}{0,8} & {$[\mathrm{~m}]$} \\
\hline & AR & EP & \\
\hline The height of the outer groove & 0,25 & 0,2 & {$[\mathrm{~m}]$} \\
\hline The width of the outer groove & 0,2 & 0,2 & {$[\mathrm{~m}]$} \\
\hline The area of the outer groove & 0,05 & 0,04 & {$\left[\mathrm{~m}^{2}\right]$} \\
\hline
\end{tabular}

The results of the selection and determination of the main parameters of schemes are presented in Table 3 . The cutting speed and depth of cut are adopted based on recommendations, as well as research results. 
Table 3. The main parameters of schemes of OCDs

\begin{tabular}{|c|c|c|c|c|}
\hline \multirow{2}{*}{ Parameter } & \multicolumn{2}{|c|}{ Disk-type } & \multicolumn{2}{|c|}{ Crown-type } \\
\hline & OCD AR & OCD EP & OCD AR & OCD EP \\
\hline The diameter of OCD, $[\mathrm{m}]$ & 0,7 & 0,6 & \multicolumn{2}{|c|}{0,2} \\
\hline The height, [m] & \multicolumn{2}{|c|}{0,2} & \multicolumn{2}{|c|}{0,2} \\
\hline The angle of coverage, $\left[{ }^{\circ}\right]$ & 74,1 & 71,5 & \multicolumn{2}{|c|}{180} \\
\hline $\begin{array}{l}\text { Minimum number of cutters on OCD } \\
\text { to ensure the CV of at least } 20 \%,[\mathrm{pcs}]\end{array}$ & 12 & 13 & \multicolumn{2}{|c|}{1} \\
\hline Number of cutters in cutting lines, [pcs] & 1 & 2 & \multicolumn{2}{|c|}{1} \\
\hline Number of cutting lines, [pcs] & \multicolumn{2}{|c|}{7} & \multirow{3}{*}{9} & \multirow{3}{*}{7} \\
\hline Total number of cutters, [pcs] & 7 & 9 & & \\
\hline $\begin{array}{l}\text { The total number of cutters taking } \\
\text { into account the minimum } \mathrm{CV},[\mathrm{pcs}]\end{array}$ & \multicolumn{2}{|c|}{14} & & \\
\hline Rotations per minute of OCD, $[\mathrm{rpm}]$ & 2,51 & 35,43 & 5,01 & 70,86 \\
\hline Actual cutting speed, $[\mathrm{m} / \mathrm{s}]$ & 0,09 & 0,37 & 0,05 & 0,74 \\
\hline
\end{tabular}

For a disk-type OCD AR, the number of cutters necessary in terms of productivity turned out to be insufficient under the condition of ensuring the CV. Therefore twice the number of cutters in the cutting lines is taken. So the total number of cutters for disk-type OCD AR and OCD EP is the same, despite different feed speeds.

The arrangement of the cutters should ensure uniformity of torque. Therefore, it is made with equal angular intervals of the cutters and cutting steps. Crown-type OCD EP and AR have different heights and patterns of arrangement of cutters. Thus, four designs of the OCDs are formed. The determination of the main parameters can be implemented using the obtained dependencies and using the developed computer model. Table 4 presents the results of determining the main parameters of the OCDs.

Table 4. The results of determining the main parameters of the OCDs

\begin{tabular}{|c|c|c|c|c|}
\hline & \multicolumn{2}{|c|}{ OCD AR } & \multicolumn{2}{|c|}{ OCD EP } \\
\hline & Disk-type & Crown-type & Disk-type & Crown-type \\
\hline Total friction path, $[\mathrm{m} / \mathrm{m}]$ & 207,27 & 164,72 & 157,03 & 131,78 \\
\hline Required torque, $[\mathrm{N} * \mathrm{~m}]$ & 2879,54 & 1358,27 & 2303,63 & 1086,62 \\
\hline The specific power consumption on cutting, $[\mathrm{kW} * \mathrm{hr} / \mathrm{m} 3]$ & 3,14 & 2,96 & 3,14 & 2,96 \\
\hline Weight of OCD with a drive, $[\mathrm{kg}]$ & 432,68 & 111,88 & 383,76 & 89,50 \\
\hline Cutting power, $[\mathrm{kW}]$ & 0,76 & 0,71 & 8,55 & 8,06 \\
\hline
\end{tabular}

Crown-type OCDs provide lower values of the total friction path, required torque, the specific power consumption on cutting, the weight of OCD with a drive, protrusion of OCD with a drive into the internal space of the geokhod, as well as permissible values of the resulting forces and torques. This led to the choice of crowntype OCD for the prototype model of geokhod at the stage of development of the design (Figure 7).

The constructive development of solutions required a number of changes to the design of the OCD:

a scheme with a cylindrical gearbox for OCD EP and OCD AR was adopted (Figure 7), the design of the mounting of the OCD drive at the same time provides access to the OCD for its maintenance and cutters replacement;

the design of the crowns was changed from cylindrical to conical due to change in the section of the blades to trapezoidal;

the number of cutters in the cutting lines was increased, the arrangement of the cutters was changed (four lag angles between the cutters, Figure 7). 
The change in the number of cutters in the cutting lines is associated with the features of the prototype geokhod. OCD should ensure the formation of the groove during the operation of the starting device at the initial destruction. In an unsteady mode of operation, the feed of the OCD can significantly exceed the calculated ones, which can lead to damage of the cutting edges. Taking into account the changes introduced into the design of the OCD using a computer model, the main operating parameters were recalculated.
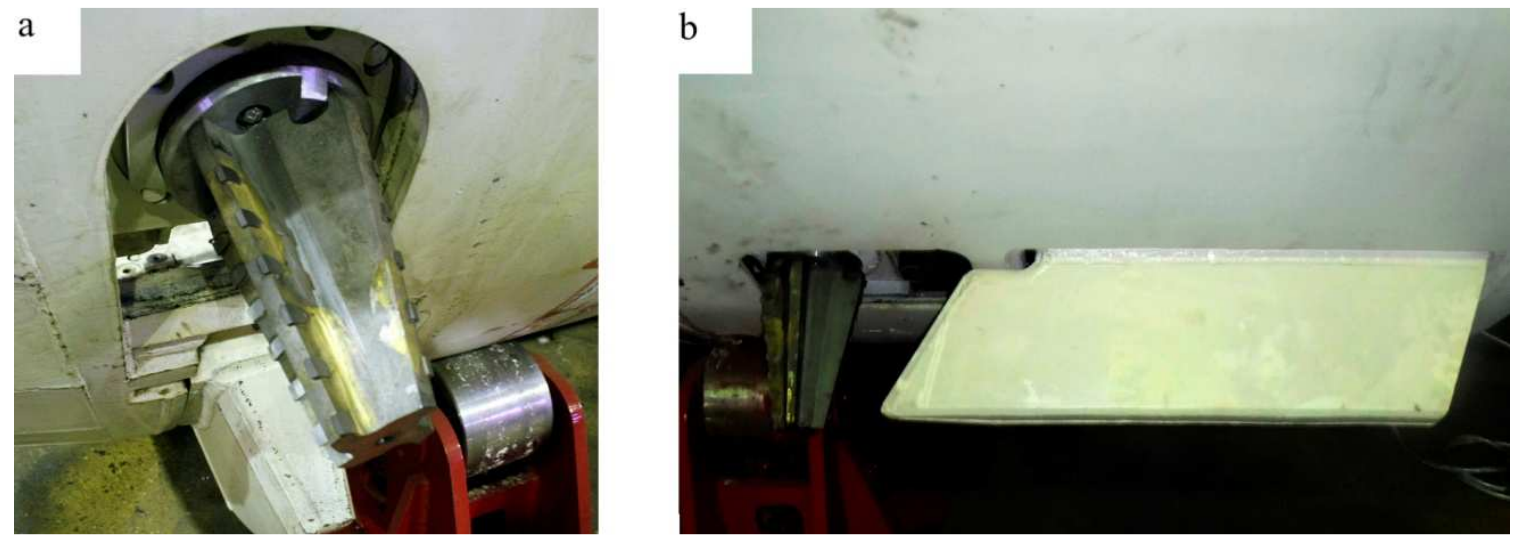

Fig 7. OCD EP (a) and OCD AR (b) of the prototype of geokhod

Based on the computations and studies, design documentation was developed for the production of OCDs of prototype geokhod. A general view of the prototype geokhod with a diameter of $3.2 \mathrm{~m}$ is presented in Figure 8 .
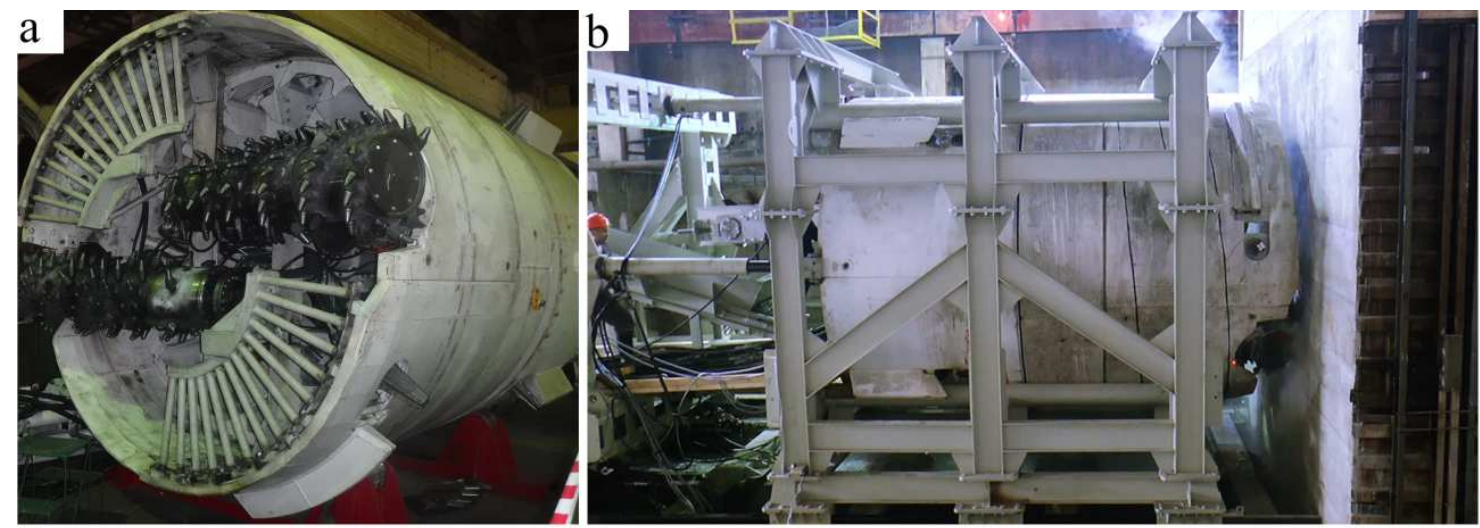

Fig 8. A general view of the prototype of geokhod (a) and test bench (b)

\section{Conclusions}

"Geowinchester technology" is a promising mining technology. The use of "Geowinchester technology" requires a significant amount of theoretical and experimental research. To conduct experimental research, a prototype geokhod $3.2 \mathrm{~m}$ in diameter was developed. When developing a prototype, the problem of choosing the OCD type was solved.

The number of cutters of OCD is determined by two factors: providing the required feed velocity and providing a torque $\mathrm{CV}$ of not higher than the preset value. At the crown-type OCD, the required feed velocities are realized with one or two cutters in the cutting lines, and the torque CV does not exceed $20 \%$ for any permissible number of cutters. On the disk-type OCD the required feed velocity is realized with the number of cutters in the cutting lines from one to four. The minimum number of cutters ensuring a torque CV on a disktype OCD is not higher than the preset value, depends on the angle of coverage and decreases when it increases. Torque CV has lower values on the crown-type OCD than disk-type OCD under otherwise equal conditions. Also, it was established that the crown-type OCDs provide lower values of the total friction path, required torque, the specific power consumption on cutting, the weight of OCD with a drive, protrusion of OCD with a drive into the internal space of the geokhod, as well as permissible values of the resulting forces and torques.

The main directions for further research:

experimental full-scale studies of the operation of crown-type OCD on a prototype geokhod model; 
the development of circuit solutions OCD combined types;

the study of the operation of the OCD of geokhod taking into account the stochastic mechanical properties of the rocks;

evaluation of the resulting efforts from the work of the OCD during the development through various geological disturbances.

\section{References}

Aksenov, V.V., Walter, A.V., Gordeyev, A.A., Kosovets, A.V., 2015. Classification of geokhod units and systems based on product cost analysis and estimation for a prototype model production. IOP Conference Series: Materials Science and Engineering 91, 012088. https://doi.org/10.1088/1757-899X/91/1/012088

Aksenov, V.V., Efremenkov, A.B., Dronov A.A., 2019. Development of a joint unit for sections of the geokhod. Journal of Mining and Geotechnical Engineering 4(7), 67-79. https://doi.org/10.26730/2618-7434-20194-67-79

Baranov, M.N., Božek, P., Prajová, V., Ivanova, T.N., Novokshonov, D.N., Korshunov, A.I., 2017. Constructing and calculating of multistage sucker rod string according to reduced stress. Acta Montanistica Slovaca 22.

Biały, W., 2014. Pomiar sił skrawania węgla z wykorzystaniem przyrządu POU-BW/01-WAP. Przegląd Górniczy 64-71.

Bialy, W., 2013. New devices used in determining and assessing mechanical characteristics of coal, in: SGEM2013 Conference Proceedings. Presented at the 13th SGEM GeoConference on Science and Technologies In Geology, Exploration and Mining, pp. 547-554.

Biały, W., Wedzicha, J., Nordin, V., 2018. Measurement of Forces During the Extraction Process. Multidisciplinary Aspects of Production Engineering 1, 117-128. https://doi.org/10.2478/mape-20180016

Bilgin, N., Copur, H., Balci, C., 2013. Mechanical excavation in mining and civil industries. CRC press.

Blashchuk, M.Yu., Kazantsev, A.A., Chernukhin, R.V., 2014. Capacity Calculation of Hydraulic Motors in geokhod Systems for Justification of Energy-Power Block Parameters. Applied Mechanics and Materials 418-425. https://doi.org/10.4028/www.scientific.net/AMM.682.418

Božek, P., 2014. Automated Detection Type Body and Shape Deformation for Robotic Welding Line, in: Swiątek, J., Grzech, A., Swiątek, P., Tomczak, J.M. (Eds.), Advances in Systems Science, Advances in Intelligent Systems and Computing. Springer International Publishing, Cham, pp. 229-240. https://doi.org/10.1007/978-3-319-01857-7_22

Cehlár, M., Rybár, P., Mihók, J., Engel, J., 2020. Analysis of investments in the mining industry. Journal of Mining and Geotechnical Engineering 1(8), 4-31. https://doi.org/10.26730/2618-7434-2020-1-4-31

Chang, S.-H., Choi, S.-W., Bae, G.-J., Jeon, S., 2006. Performance prediction of TBM disc cutting on granitic rock by the linear cutting test. Tunnelling and Underground Space Technology, Safety in the Underground Space - Proceedings of the ITA-AITES 2006 World Tunnel Congress and 32nd ITA General Assembly 21, 271. https://doi.org/10.1016/j.tust.2005.12.131

Chernukhin, R.V., Dronov, A.A., Blashchuk, M.Y., 2015. The application of the analytic hierarchy process when choosing layout schemes for a geokhod pumping station. IOP Conf. Ser.: Mater. Sci. Eng. 91, 012086. https://doi.org/10.1088/1757-899X/91/1/012086

Dogruoz, C., Bolukbasi, N., Rostami, J., Acar, C., 2016. An Experimental Study of Cutting Performances of Worn Picks. Rock Mech Rock Eng 49, 213-224. https://doi.org/10.1007/s00603-015-0734-x

Ermakov, A., n.d. Estimation of Coefficient of Variation of Torque of Geokhods out of Cross Section Cutting Drum. Mining equipment and electromechanics 8, 25-29.

Hekimoglu, O.Z., Fowell, R.J., 1991. Theoretical and practical aspects of circumferential pick spacing on boom tunnelling machine cutting heads. Mining Science and Technology 13, 257-270. https://doi.org/10.1016/0167-9031(91)90397-U

Hurt, K.G., MacAndrew, K.M., 1985. Cutting efficiency and life of rock-cutting picks. Mining Science and Technology 2, 139-151. https://doi.org/10.1016/S0167-9031(85)90357-3

Jang, J.-S., Yoo, W.-S., Kang, H., Cho, J.-W., Jeong, M.-S., Lee, S.-K., Cho, Y.-J., Lee, J.-W., Rostami, J., 2016. Cutting head attachment design for improving the performance by using multibody dynamic analysis. International Journal of Precision Engineering and Manufacturing 17, 371-377.

Jedliński, Ł., Gajewski, J., 2019. Optimal selection of signal features in the diagnostics of mining head tools condition. Tunnelling and Underground Space Technology 84, 451-460. https://doi.org/10.1016/j.tust.2018.11.042

Khoreshok, A., Aksenov, V.V., Ananiev, K.A., Ermakov, A.N., 2018. Study of the Rational Number of Cutters in the Cutting Lines of Cutting Drum of Geokhod, in: Proceedings of the 9th China-Russia Symposium 
"Coal in the 21st Century: Mining, Intelligent Equipment and Environment Protection" https://doi.org/doi:10.2991/coal-18.2018.40

Khoreshok, A., Ananyev, K., Ermakov, A., Golikova, E., 2019. Application of Multi-Criteria Decision Analysis for Choice Geokhods Cutting Head. E3S Web Conf. 105, 03010. https://doi.org/10.1051/e3sconf/201910503010

Kim, Y., Bruland, A., 2015. A study on the establishment of Tunnel Contour Quality Index considering construction cost. Tunnelling and Underground Space Technology 50, 218-225. https://doi.org/10.1016/j.tust.2015.07.010

Li, X., Huang, B., Ma, G., Zeng, Q., 2013. Study on Roadheader Cutting Load at Different Properties of Coal and Rock. The Scientific World Journal 2013, 624512. https://doi.org/10.1155/2013/624512

Sadovets, V.Y., Beglyakov, V.Y., Aksenov, V.V., 2015. Development of math model of geokhod bladed working body interaction with geo-environment. IOP Conf. Ser.: Mater. Sci. Eng. 91, 012085. https://doi.org/10.1088/1757-899X/91/1/012085

Trofimov, V.A., Kubrin, S.S., Filippov, Y.A., Kharitonov, I.L., 2019. Numerical modeling of stress-strain state for host rock mass and thick gently dipping coal seam after mining completion in extraction panel. Mining Informational and Analytical Bulletin 2019, 42-56. https://doi.org/10.25018/0236-1493-2019-08$0-42-56$

Wingquist, C.F., Hanson, B.D., 1987. Bit wear-flat temperature as a function of depth of cut and speed. US Department of the Interior, Bureau of Mines.

Xuefeng, L., Shibo, W., Shirong, G., Malekian, R., Zhixiong, L., 2018. Investigation on the influence mechanism of rock brittleness on rock fragmentation and cutting performance by discrete element method. Measurement 113, 120-130. https://doi.org/10.1016/j.measurement.2017.07.043 